\title{
A rapid method for identification of Mycobacterium species by polyacrylamide gel electrophoresis of soluble cell proteins
}

\author{
A. DE JONG, A. H. HOENTJEN and A. G. M. VAN DER ZANDEN \\ Regional Institute for Public Health, Dr. H. G. Gooszenstraat 1, 7415 CL Deventer, The Netherlands
}

\begin{abstract}
Summary. The sodium dodecyl sulphate-polyacrylamide gel electrophoresis (SDS-PAGE) profiles of an easily and rapidly prepared soluble protein fraction were used in conjunction with conventional techniques to identify different strains of $M y$ cobacterium tuberculosis, $M$. bovis, $M$. bovis BCG, $M$. africanum, $M$. avium, $M$. kansasii, $M$. marinum, $M$. gastri, $M$. simiae and $M$. malmoense. Complete concordance of results from both methods was obtained with all species except those of the $M$. tuberculosis complex. With the SDS-PAGE technique, all strains of the $M$. tuberculosis complex were recognised as belonging to one species. By visual analysis of the SDS-PAGE polypeptide profiles, only minor differences between strains of the same species were seen and each species showed a characteristic polypeptide profile. Quantitation of the data by calculation of the Dice coefficient of similarity of the band positions obtained by densitometry indicated that the similarity between different strains of one species was $90-100 \%$ and the similarity between the species was in the range $30-45 \%$. The results indicate that SDS-PAGE is a simple and rapid method for identifying mycobacterial strains.
\end{abstract}

\section{Introduction}

In a routine laboratory, the identification of slowly growing mycobacterial strains on the basis of various biochemical reactions is very time consuming. ${ }^{1,2}$ Only strains belonging to the Mycobacterium tuberculosis complex are fairly easily recognised biochemically, or by hybridisation with a DNA-probe ${ }^{3}$ or by use of monoclonal antibodies. ${ }^{4}$ However, the number of strains isolated from clinical material and not belonging to the $M$. tuberculosis complex is increasing. ${ }^{5}$ In our laboratory up to $40 \%$ of mycobacterial isolates do not belong to the $M$. tuberculosis complex; all these isolates must be identified, because not all species that do not come within the $M$. tuberculosis complex are potentially pathogenic in man. Moreover, in the clinical setting this needs to be done easily and rapidly. Furthermore, the study of infectious diseases depends on accurate identification of isolates.

For all these reasons, we sought a suitable method for identifying all mycobacterial species. Several investigators have used sodium dodecyl sulphatepolyacrylamide gel electrophoresis (SDS-PAGE) of soluble bacterial polypeptides successfully as a taxonomic tool, ${ }^{6,7}$ and others have shown that densitometric analysis of stained gels provides data suitable for numerical taxonomy. ${ }^{8,9}$ The aim of this study was to evaluate the usefulness of SDS-PAGE as a tool for identifying mycobacterial isolates. This paper de-

Received 25 Oct. 1989; revised version accepted 16 May 1990. scribes our results with SDS-PAGE of soluble polypeptides of strains of the $M$. tuberculosis complex and of seven other mycobacterial species.

\section{Material and methods}

\section{Bacterial isolates and culture conditions}

A total of 191 clinical isolates was studied, comprising strains of $M$. tuberculosis (50 isolates), $M$. bovis (16), $M$. africanum (12), $M$. bovis BCG (13), $M$. avium (50), M. kansasii (9), M. marinum (11), M. gastri (10), M. simiae (3), M. xenopi (7), M. malmoense (10), together with the following reference strainsM. tuberculosis ATCC 35836, M. gastri ATCC 15754, $M$. marinum ATCC 927, M. simiae ATCC 25275 and $M$. xenopi ATCC 19250. The reference strains were obtained from the American Type Culture Collection, Rockville, MD. All strains were identified at our laboratory as described elsewhere. ${ }^{10,11}$

Mycobacterial strains were grown routinely on Coletsos slants (Diagnostics Pasteur, Marnes-la-Coquette, France) ${ }^{12}$ or in Modified Dubos Broth (MDB: Middlebrook 7H9 Broth, Difco, $4 \cdot 7 \mathrm{~g}$; Bactocasitone, Difco, $0.5 \mathrm{~g}$; L-asparagine $4.0 \mathrm{~g}$; L-glutamic acid $1.0 \mathrm{~g}$; sodium pyruvate $1.6 \mathrm{~g}$; yeast extract $1.0 \mathrm{~g}$; biotin $5.0 \mathrm{mg}$; glycerol $50 \mathrm{ml}$; distilled water $950 \mathrm{ml}$; $\mathrm{pH} 6.6$ at $25^{\circ} \mathrm{C}$; after sterilisation at $121^{\circ} \mathrm{C}$ for $15 \mathrm{~min}, 50 \mathrm{ml}$ inactivated new born calf serum, Gibco, was added). All chemicals were from Sigma, St Louis, MO, USA 
unless otherwise stated. Acrylamide was from Serva Feinbiochemica, Heidelberg, Germany.

\section{Preparation of samples for SDS-PAGE}

Bacterial suspensions were prepared either by scraping growth from Coletsos slants or by growing the bacteria in $25-\mathrm{ml}$ volumes of MDB at $35^{\circ} \mathrm{C}$ for 16 weeks and harvesting by centrifugation at $5000 \mathrm{~g}$ for $15 \mathrm{~min}$ at $4^{\circ} \mathrm{C}$. In both cases, the cell mass was washed twice in $25 \mathrm{ml}$ of $10 \mathrm{~mm}$ Tris-HCl buffer, $\mathrm{pH} 8.2$ at $4^{\circ} \mathrm{C}$. The cell suspension was transferred to a $1 \cdot 5-\mathrm{ml}$ Eppendorf vessel and the wet weight of the cell mass was determined after centrifugation and removal of the supernate. Then, for each $1 \mathrm{mg}$ of cell mass, $2 \mu \mathrm{l}$ of buffer ( $5 \mathrm{~mm}$ Tris- $\mathrm{HCl}, \mathrm{pH} \mathrm{7.3)}$ was added and the bacterial cells were resuspended by sonication for $30 \mathrm{~s}$ at $60 \%$ pulse and $20 \%$ maximal power in an Ultrasonics type W225 sonifier (Heat Systems-Ultrasonics Inc., Farmingdale, NY, USA) equipped with a microtip. This procedure yielded a homogeneous suspension.

The cell suspension in the Eppendorf vessel was now quickly frozen in cold $\left(-70^{\circ} \mathrm{C}\right)$ ethanol and then thawed in water at $40^{\circ} \mathrm{C}$. This freeze and thaw procedure was repeated three times to release membrane proteins. The suspension was then centrifuged at $10000 \mathrm{~g}$ for $10 \mathrm{~min}$ at $4^{\circ} \mathrm{C}$ and the clear supernate, called the soluble protein fraction, was used for electrophoresis. The soluble protein fractions were stored at $-70^{\circ} \mathrm{C}$.

The soluble protein fraction was mixed in $3: 1$ proportions with $0.2 \mathrm{M}$ Tris- $\mathrm{HCl}$ buffer, $\mathrm{pH} 6 \cdot 8$, containing SDS $8 \% \mathrm{w} / \mathrm{v}$, sucrose $40 \% \mathrm{w} / \mathrm{v}, 2$-mercaptoethanol $20 \% \mathrm{v} / \mathrm{v}$ and bromophenol blue $0.016 \% \mathrm{w} / \mathrm{v}$. Before application to the gel, the samples were boiled for $10 \mathrm{~min}$ and centrifuged for $5 \mathrm{~min}$ at $10000 \mathrm{~g}$ and the supernate was used for gel electrophoresis.

\section{Gel electrophoresis}

SDS-PAGE analysis of the soluble protein fraction sample was performed by a modified version of the technique of Laemmli. ${ }^{13}$ A slab gel $(160 \times 120 \times$ $1.0 \mathrm{~mm}$ ), built up as a vertical $10-20 \%$ gradient (acrylamide: bisacrylamide, ratio $28: 1$ ) in $0.375 \mathrm{M}$ Tris- $\mathrm{HCl}$, $\mathrm{pH} 8 \cdot 8$, SDS $0 \cdot 1 \% \mathrm{w} / \mathrm{v}$, was used. The 10 $\mathrm{mm}$ stacking gel was acrylamide: bis-acrylamide (ratio $29: 13 \%$ in 0.125 м Tris- $\mathrm{HCl}$, pH 6.8, SDS $0.2 \% \mathrm{w} / \mathrm{v}$. A sample $(10 \mu \mathrm{l}$, containing $60-80 \mu \mathrm{g}$ of protein estimated by quantitative densitometry) of the soluble protein fraction was applied to each well. The gel was run for $16 \mathrm{~h}$ at a constant current of $10 \mathrm{~mA}$ without cooling or for $4 \mathrm{~h}$ at a constant current of $40 \mathrm{~mA}$ with cooling $\left(10^{\circ} \mathrm{C}\right)$ in a Biorad Protean II gel apparatus. The gel was removed and stained in Coomassie Brilliant Blue R-250 0.25\% w/v in methanol: acetic acid: water $(25: 10: 65 \mathrm{v}: \mathrm{v}: \mathrm{v})$ and destained in the same solvent mixture. Low mol. wt protein markers (Pharmacia, Uppsala, Sweden) were run in the same gel to allow the estimation of mol. wts. Densitometric analysis was performed with an LKB 2202 Ultroscan Laser Densitometer with Nelson software.

\section{Comparison of polypeptide profiles}

The average similarity between any two strains was assessed by use of the coefficient of Dice ${ }^{14}$ whereby: average percentage similarity $(\% \mathrm{~S})=($ number of matching bands $\times 2$ )/(total number of bands in both strains). The calculation of similarity was based on a visual comparison of the densitometric profiles and was done independently by two individuals. Extracts of strains were run several times to confirm the results.

\section{Results}

The complexities of the polypeptide profiles obtained by the method used were similar to those obtained after cell disruption by high energy sonication ( $5 \mathrm{~min}, 50 \%$ pulse, $80 \%$ of a maximum power of $45 \mathrm{~W})$ (data not shown). Furthermore, the size of the sample of the soluble protein fraction did not affect greatly the complexity of the electrophoretogram. For instance, if the size of the sample of the soluble protein fraction of $M$. tuberculosis strains was increased from $30 \mu \mathrm{g}$ to $250 \mu \mathrm{g}$ of protein, the number of protein bands in the electrophoretogram decreased from 43 to

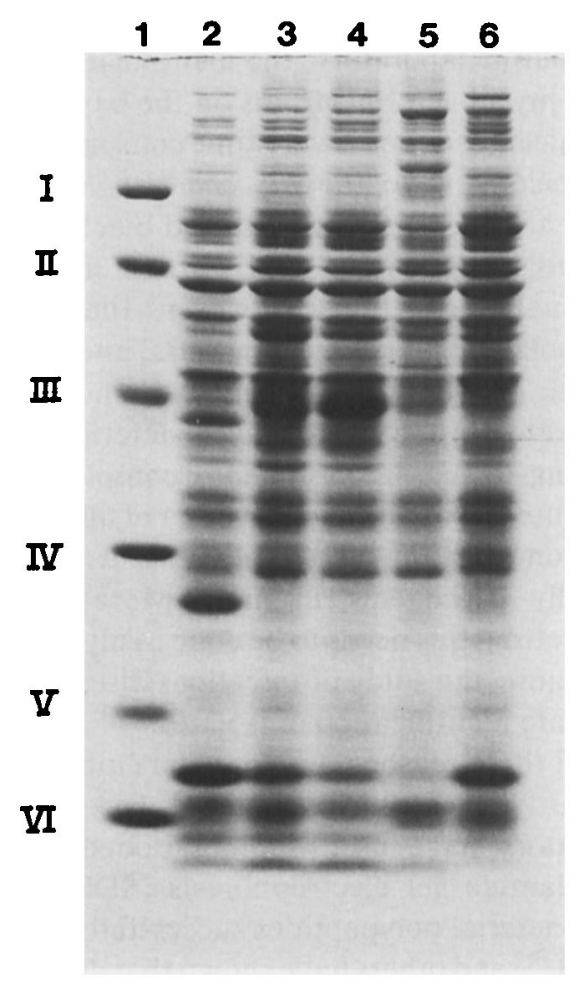

Fig. 1. Soluble protein fraction polypeptide profiles of $M$. tuberculosis tub 1159 cultured on five different media. Track 1: mol. wt markers-I. phosphorylase b $(94 \mathrm{Kda})$; II. bovine albumin $(67 \mathrm{Kda})$; III. ovalbumin $(43 \mathrm{Kda})$; IV. carbonic anhydrase $(30 \mathrm{Kda})$; V. trypsin inhibitor $(20.1 \mathrm{Kda})$; VI. lactalbumin $(14.4 \mathrm{Kda})$. 2-6: The profile obtained after culture (2) on $7 \mathrm{H} 10$ slants, (3) on Coletsos slants (bovine type), (4) on Coletsos slants (human type), (5) in MDB, (6) on MDB with agar $1 \% \mathrm{w} / \mathrm{v}$ slants. 


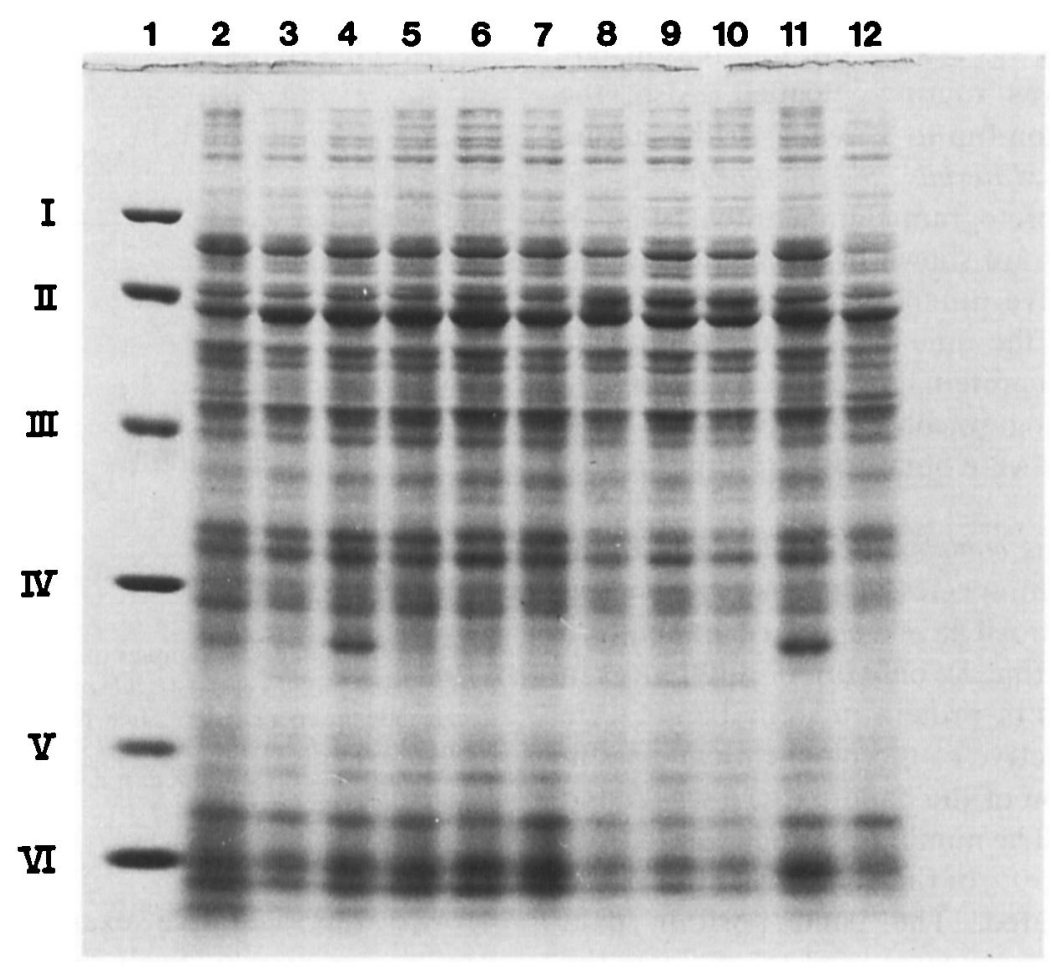

Fig. 2. Soluble protein fraction polypeptide profiles of species of the $M$. tuberculosis complex. Track 1 : mol. wt markers (see fig. 1); 2-4: $M$. tuberculosis strains tub 1129 , tub 1159 and tub 1013 respectively; 5-7: M. bovis strains bov 1225 , bov 1250 and bov $980 ; 8-10: M$. africanum strains afr 3001, afr 3055 and Myc 4470; 11 and 12: M. bovis-BCG strains BCG 1193 and BCG 1228 (strain BCG 1228 is the Dutch vaccine strain).

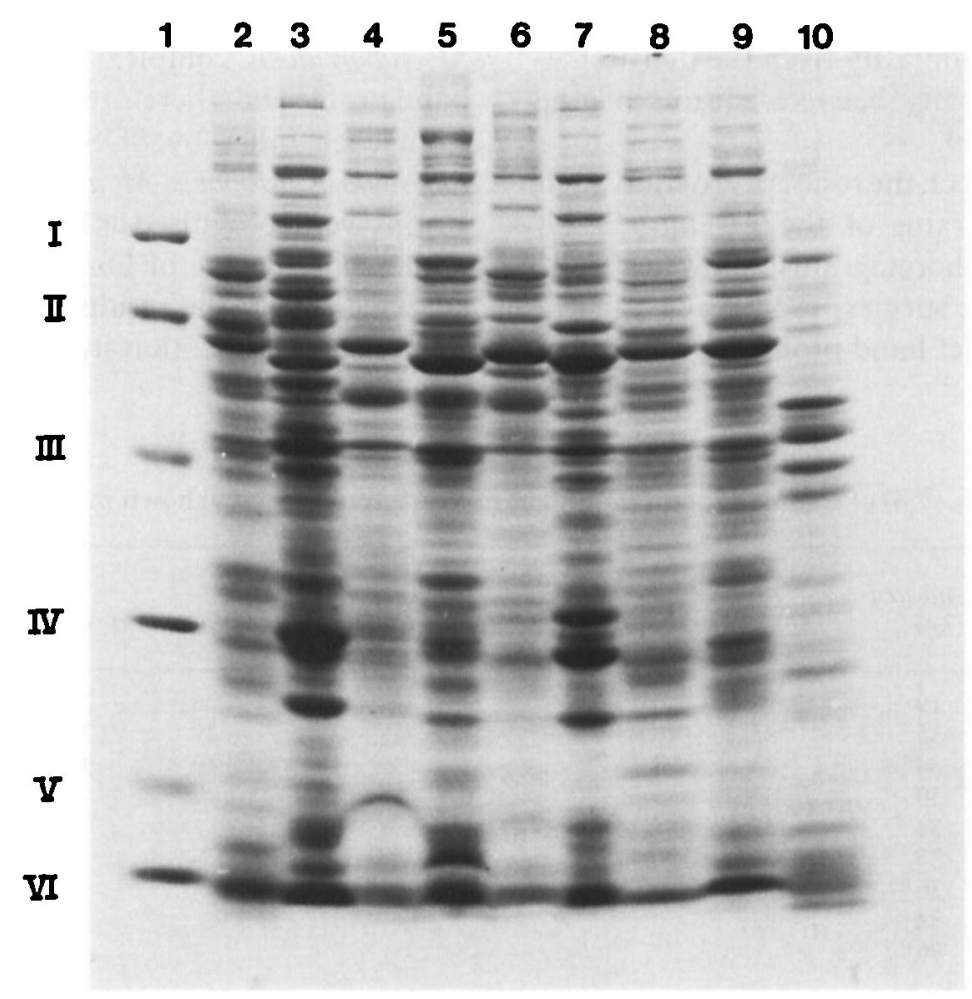

Fig. 3. Soluble protein polypeptide profiles of eight mycobacterial species and Streptococcus pyogenes. Track 1 : mol. wt markers (see fig. 1); 2: $M$. tuberculosis ATCC 35836; 3: M. avium AV 942; 4: M. kansasii KANS 991; 5: M. marinum ATCC 927; 6: M. gastri ATCC 15754; 7 : M. simiae ATCC 25275; 8: M. xenopi ATCC 19250; 9: M. malmoense MYC 6138; 10: S. pyogenes. 
39 and the Dice coefficient of similarity between the electrophoretograms was $>90 \%$. For that reason, 60 $80 \mu \mathrm{g}$ of protein was routinely loaded. Also, the duration of incubation (up to 6 weeks) or the culture medium used (see Materials and methods) did not affect the electrophoretogram significantly. In fig. 1, electrophoretograms are shown of an $M$. tuberculosis strain cultured on five different media. Apart from some differences in the amount of protein in some bands, only one extra protein band of $26 \mathrm{Kda}$ was seen in the electrophoretogram obtained from the $7 \mathrm{H} 10$ slant. Similar results were obtained with other mycobacterial species.

The $M$. tuberculosis complex. A total of 91 strains belonging to different species of the $M$. tuberculosis complex was studied. All gave a similar band pattern by visual judgement (fig. 2); only minor differences in the relative amounts of protein in some bands were noted. Thus, irrespective of the biochemical classifcation, little variation of the band pattern was found between the strains. The number of bands varied from 41 to 43 and at least $90 \%$ of the bands were present in all strains investigated. The band position data obtained by densitometry were used to calculate the Dice coefficient of similarity and so the visual judgement in terms of co-migrating bands was given a quantitative assessment. The average Dice coefficient between strains was $96 \%$ (range $92-100 \%$ ).

Other mycobacterial species. A total of seven other mycobacterial species was studied. Each species yielded a characteristic electrophoretogram; however, electrophoretograms of strains belonging to one species showed little variation by visual judgement. A more objective assessment was made by calculating the Dice coefficient of similarity from the densitometric profiles. The similarity between strains of one species was $>90 \%$ (table).

Therefore, in this respect, the results were equivalent to those found with strains of the $M$. tuberculosis complex. The electrophoretograms showed 35-45 bands, depending on the species; each species gave a characteristic and distinct band profile (fig. 3). In fig.
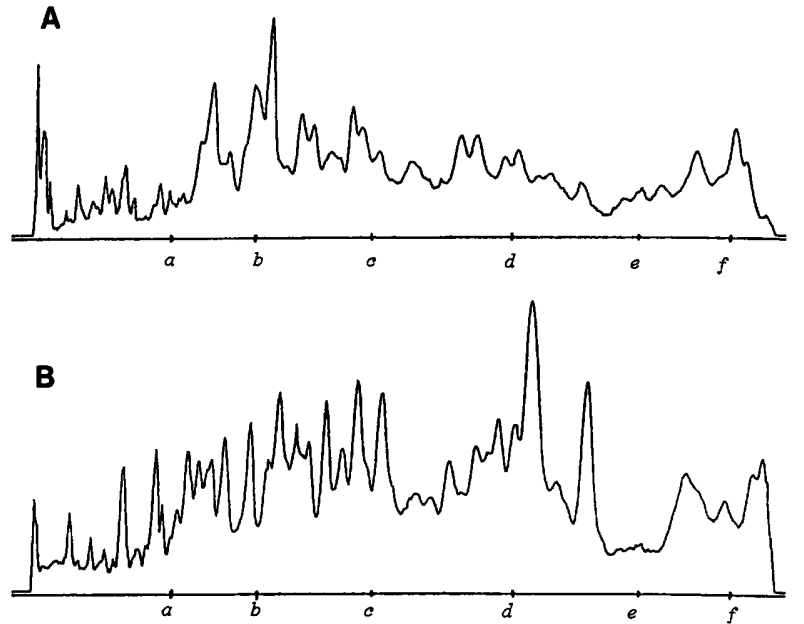

Fig. 4. Representative examples of densitometric profiles of SDSPAGE band profiles of (A) $M$. tuberculosis and (B) $M$. simiae as used to calculate the coefficient of Dice. Mol. wt markers : $a$, phosphorylase b ( $94 \mathrm{Kda}) ; b$, bovine albumin (67 Kda); $c$, ovalbumin (43 Kda); $d$, carbonic anhydrase $(30 \mathrm{Kda}) ; e$, trypsin inhibitor $(20.1 \mathrm{Kda}) ; f$, lactalbumin (14.4 Kda).

4, two representative examples of densitometric profiles are shown. Such densitometric profiles are more suitable for mutual comparison and, therefore, also more appropriate for identification than are electrophoretograms. The Dice coefficient of similarity between strains of different species varied from $30 \%$ to $45 \%$ (table).

\section{Discussion}

This study showed that all strains belonging to the $M$. tuberculosis complex had a similar SDS-PAGE band profile and, therefore, could not be differentiated from each other by SDS-PAGE band profiles. $M$. tuberculosis, $M$. bovis, $M$. africanum and $M$. bovis-BCG strains were recognised as belonging to a single species with a high degree of homogeneity. This result is in agreement with the results of DNA homology ${ }^{15}$ and numerical classification studies.

Table. Percentage similarity $(\% \mathbf{S})$ of soluble protein profiles of mycobacterial species shown in fig. 3

\begin{tabular}{|c|c|c|c|c|c|c|c|c|c|}
\hline & $\begin{array}{c}\text { M. tubercu- } \\
\text { losis }\end{array}$ & M. avium & M. kansasii & $M$. marinum & M. gastri & M. simiae & M. xenopi & $\begin{array}{l}\text { M. mal- } \\
\text { moense }\end{array}$ & $\begin{array}{c}\text { Streptococcus } \\
\text { pyogenes }\end{array}$ \\
\hline Streptococcus pyogenes* & 19 & 23 & 19 & 23 & 21 & 26 & 24 & 24 & $94 \dagger$ \\
\hline M. malmoense & 35 & 38 & 33 & 41 & 37 & 29 & 31 & $98+$ & \\
\hline M. xenopi & 34 & 33 & 35 & 39 & 28 & 40 & $91+$ & & \\
\hline M. simiae & 30 & 41 & 45 & 36 & 33 & $97+$ & & & \\
\hline M. gastri & 31 & 37 & 34 & 31 & $95+$ & & & & \\
\hline$M$. marinum & 35 & 38 & 41 & $94 \dagger$ & & & & & \\
\hline M. kansasii & 36 & 37 & $96+$ & & & & & & \\
\hline M. avium & 34 & $92+$ & & & & & & & \\
\hline M. tuberculosis & $96+$ & & & & & & & & \\
\hline
\end{tabular}

* Streptococcus pyogenes was used to determine the $\% \mathrm{~S}$ between an unrelated species and the mycobacterial species. The $\% \mathrm{~S}$ values between the mycobacterial species were not corrected for this "base line similarity".

$\dagger$ Average $\% \mathrm{~S}$ of the soluble protein profiles of a maximum of 10 strains of one species. 
Our results with the other seven species show seven species-specific SDS-PAGE band profiles. These species-specific band profiles can easily be differentiated from each other and from that of the $M$. tuberculosis complex. The percentage similarity between these eight band profiles, as described in this paper, are significantly heterogeneous, ranging from $30 \%$ to $45 \%$.

From these results we conclude that the $M$. tuberculosis complex, $M$. avium, $M$. kansasii, $M$. marinum, M. gastri, $M$. simiae and $M$. malmoense are eight distinct mycobacterial species. The low level of relatedness between $M$. avium and $M$. marinum $(38 \%)$ or $M$. simiae $(33 \%)$ that we found is not in agreement with the numerical results $(91 \%$ relatedness) given by Tsukamura, ${ }^{1}$ but is in agreement with results of DNA homology studies. ${ }^{15,16}$

The development of a new method for determination

\section{References}

1. Tsukamura M. Numerical classification of 280 strains of slowly growing mycobacteria. Microbiol Immunol 1983; 27 : 315334.

2. Wayne LG, Krichevsky MI, Portyrata D, Jackson CK Diagnostic probability matrix for identification of slowly growing mycobacteria in clinical laboratories. $J$ Clin Microbiol 1984; 20: 722-729.

3. Patel R J, Piessons WF, David JR, Wirth DF. A cloned DNA fragment for identification of Mycobacterium tuberculosis. Rev Infect Dis 1989; 11 Suppl 2:411-419.

4. Kadival GV, Chaparas SD. Production characterization, and species specificity of five monoclonal antibodies to $\mathrm{Myco}$ bacterium tuberculosis. J Clin Microbiol 1987; 25 : 76-80.

5. Woods GL, Washington JA. Mycobacteria other than $M y c o-$ bacterium tuberculosis: review of microbiologic and clinical aspects. Rev Infect Dis 1987; 9: 275-294.

6. Clink J, Pennington TH. Staphylococcal whole-cell polypeptide analysis : evaluation as a taxonomic and typing tool. $J \mathrm{Med}$ Microbiol 1987; 23: 41-44.

7. Nordstrom KM. Polyacrylamide gel electrophoresis (PAGE) of whole-cell proteins of cutaneous Propionibacterium species. J Med Microbiol 1985; 19: 9-14.

8. Jackman PJH. Classification of Corynebacterium species from axillary skin by numerical analysis of electrophoretic protein patterns. $J$ Med Microbiol $1982 ; 15$ : 485-492.

9. Kersters K, De Ley J. Identification and grouping of bacteria of mycobacterial species is desirable because a growing number of mycobacterial infections are caused by strains that do not belong to the $M$. tuberculosis complex. To come to a conclusion about the clinical significance of an isolate, it has first to be identified and in the clinical setting it is important to obtain an unambiguous result as soon as possible. The method of identification that we describe makes it possible to identify all mycobacterial isolates within 10 days. More work is necessary to evaluate the usefulness of the method for mycobacterial species other than those described in this paper. We have initiated studies to evaluate this approach with the $M$. avium complex and related species.

We thank Professor D. M. Maclaren of the Free University, Amsterdam for his support and Miss Karen Wichgers for typing the manuscript. by numerical analysis of their electrophoretic protein patterns. J Gen Microbiol 1975; 87 : 333-342.

10. Goodfellow M, Wayne LG. Taxonomy and nomenclature. In Ratledge C, Stanford J (ed) The biology of the mycobacteria. London, Academic Press 1982: 471-521.

11. Sommers HM, Good RC. Mycobacterium. In: Lennette EH, Balows A, Hausler WJ, Shadomy HJ (eds) Manual of clinical microbiology, 4th edn. Washington DC, American Society for Microbiology. 1985: 216-248.

12. Coletsos PJ. Milieux et modalités de culture adaptés a la réanimation et a la multiplication in vitro de $M y$ cobacterium tuberculosis de vitalité réduite, de viabilitè éphémère, ou en état de quiescence. Ann Inst Pasteur 1960; 99: 475-495.

13. Laemmli UK. Cleavage of structural proteins during the assembly of the head of bacteriophage T4. Nature 1970; 227: $680-685$.

14. Dice LR. Measures of the amount of ecologic association between species. Ecology 1945; 26 : 297-302.

15. Imaeda $T$. Deoxyribonucleic acid relatedness among selected strains of Mycobacterium tuberculosis, Mycobacterium bovis, Mycobacterium bovis BCG, Mycobacterium microti and Mycobacterium africanum. Int J Syst Bacteriol 1985; 35: 147-150.

16. Baess I, Magnusson M. Classification of Mycobacterium simiae by means of comparative reciprocal intradermal sensitin testing on guinea-pigs and deoxyribonucleic acid hybridization. Acta Path Microbiol Immunol Scand Sect B 1982; 90: 101-107. 